\title{
Misconceptions and Perceptions on Breast Cancer Risk in Kilifi South Subcounty
}

Leonard Kiti Alii*

Pwani University Kilifi, Coast Kenya, Kenya

\begin{abstract}
The objective was to find out the misconceptions and perceptions associated with breast cancer in Kilifi south subcounty. A survey was conducted on a random sample of women in Kilifi South with no history of breast cancer. The Survey instrument were questionnaires which included measures of perceptions and misconceptions of breast cancer for themselves and for the average woman, perceptions of risk factors that influenced their risk and the average woman's risk for breast cancer. Descriptive statistics, chi-square tests and spearman's correlations were used to analyze the data A spearman's correlation coefficient showed that, women's perceptions on Witchcraft as a cause for cancer were related to Cancer being a curse. The correlation was statistically significant at $5 \%$ level of significance, $(R=0.5182, S=4462.4$, $\mathrm{p}=0.0003016)$. A Pearson's chi-square test also confirmed this $\left(\chi^{2}=47.407, \mathrm{P}\right.$-value $\left.=0.000\right)$. This probably explains why the uptake of screening services provided by the government in the health centers across the counties has not been effective.
\end{abstract}

Keywords: Breast cancer; Misconceptions; Perceptions; Screening; Healthcare

\section{Introduction}

Health care professionals are increasingly involved in providing information and advice to women who are concerned about their risk for breast cancer. Breast cancer is the most frequently occurring form of cancer worldwide among women, and the second highest cause of cancer deaths [1]. According to Farley et al. [2], it is estimated that breast cancer cases could rise to 2.1 million by 2030. In Kenya, it is estimated that cancer is the third leading cause of death in the country after infectious and cardiovascular diseases (Ministry of public health and sanitation and Ministry of medical services - Kenya [3]). Counselling about breast cancer risk, however, may be complicated by the misconceptions and myth that surround breast cancer in different cultural settings, and the relative importance of breast cancer risk factors. Cancer in societies is still associated with some misconceptions. Some women believe that cancer is associated with witchcraft. There are also those who believe that breast cancer is a curse from God. Some studies also have indicated that cancer may be as a result of breast feeding though the literature on this is very scarce. The study sought to understand the extent of knowledge in Kilifi south within Kilifi county Kenya. The study targeted the women within the child bearing age. The data was obtained through a questionnaire that was administered randomly to 216 respondents. The investigators sought to understand the beliefs and misconceptions surrounding breast cancer. This was in an attempt to find out the barriers in the uptake of screening services that are provided amid government efforts to create awareness. Despite widespread availability of risk information, many women hold inaccurate perceptions of their own risk and the population risk for breast cancer. Misperceptions have been linked to innumeracy limited knowledge about breast cancer denial, perceived lack of control over the disease and anxiety or excessive breast cancer worry.

\section{Background information of Kilifi South subcounty}

Kilifi South Sub County is Kilifi County is located in the in Kilifi County and covers an area of approximately 400.60 square kilometers. According to the Kenya population and housing census, august 2009 the sub county was home to 171,607 people then which comprised of 82,733 male (48.21\%) and 88,874 female (51.79\%). Kilifi County has some of the poorest social economic indicators in the country with a poverty rate of $72 \%$ and a relatively low literacy level which exposes a significant proportion of the population to various health risk factors.

\section{Methodology}

A survey was conducted on women in the child bearing age of 1549 years in Kilifi South with no history of breast cancer. According to the Kenya population and housing census, august 2009 the sub county was home to 171,607 people then which comprised of 82,733 male (48.21\%) and 88,874 female (51.79\%). A sample size of two hundred and sixteen subjects was randomly selected. The Survey instrument were questionnaires which included measures of perceptions and misconceptions of breast cancer for themselves and for the average woman, perceptions of risk factors that influenced their risk and the average woman's risk for breast cancer. The responses were classified according to level of education and age. Analysis was done using chisquare tests; Spearman's rank correlation coefficients, frequency tables and bar graphs.

\section{Results and Discussions}

Descriptive statistics, chi-square tests and spearman's correlations were used to analyze the data. Of those sampled $15.4 \%$ were aged between 15-19, 43.6\% were between $20-29,25.6 \%$ were aged between $30-39$ years and $15.4 \%$ were aged between $40-49.76 .9 \%$ were married, $2.6 \%$ were separated, $7.7 \%$ were single and $12.8 \%$ were widowed. $10.2 \%$ were holders of a bachelor's degree, $12.8 \%$ were high School graduates. $51.3 \%$ were primary dropouts, $25.6 \%$ had no formal education. Figures 1 and 2 shows the distribution of the respondents by age, marital status, level of education and their occupation.

*Corresponding author: Alii LK, Pwani University Kilifi, Coast Kenya, Kenya, Tel: 0722917294; E-mail: leonardalii@yahoo.com

Received December 08, 2017; Accepted February 21, 2017; Published February 24, 2017

Citation: Alii LK (2017) Misconceptions and Perceptions on Breast Cancer Risk in Kilifi South Subcounty. J Biom Biostat 8: 336. doi:10.4172/2155-6180.1000336

Copyright: ( 2017 Alii LK. This is an open-access article distributed under the terms of the Creative Commons Attribution License, which permits unrestricted use, distribution, and reproduction in any medium, provided the original author and source are credited. 


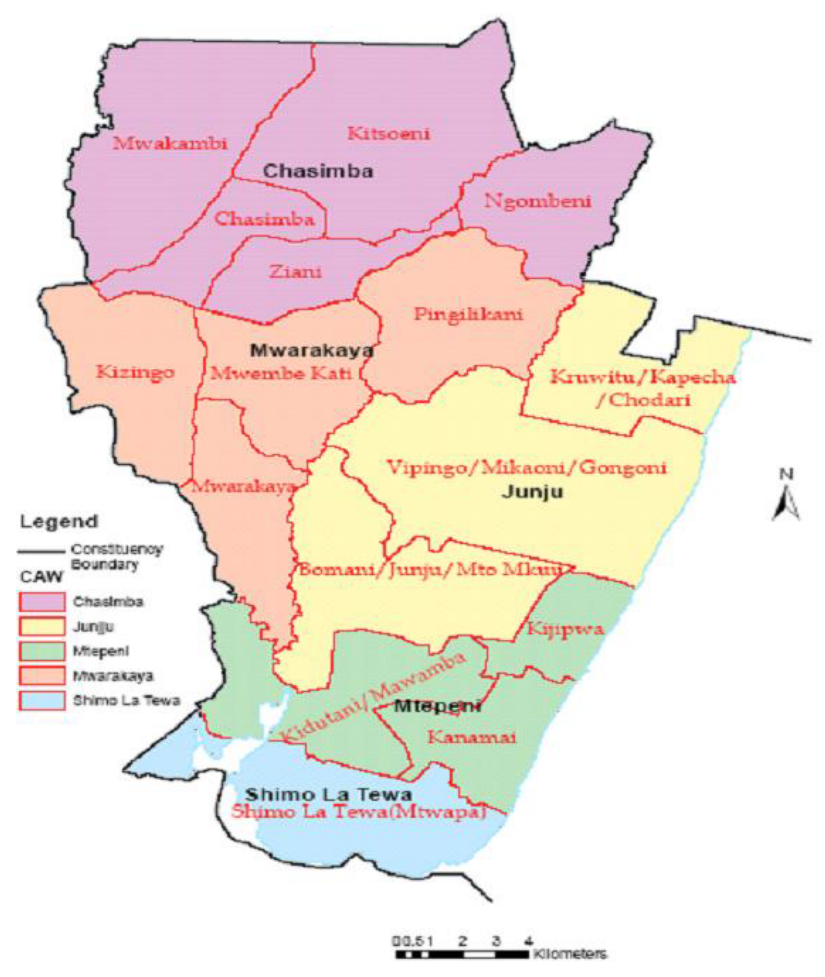

Figure 1: Map of Kilifi south sub county.
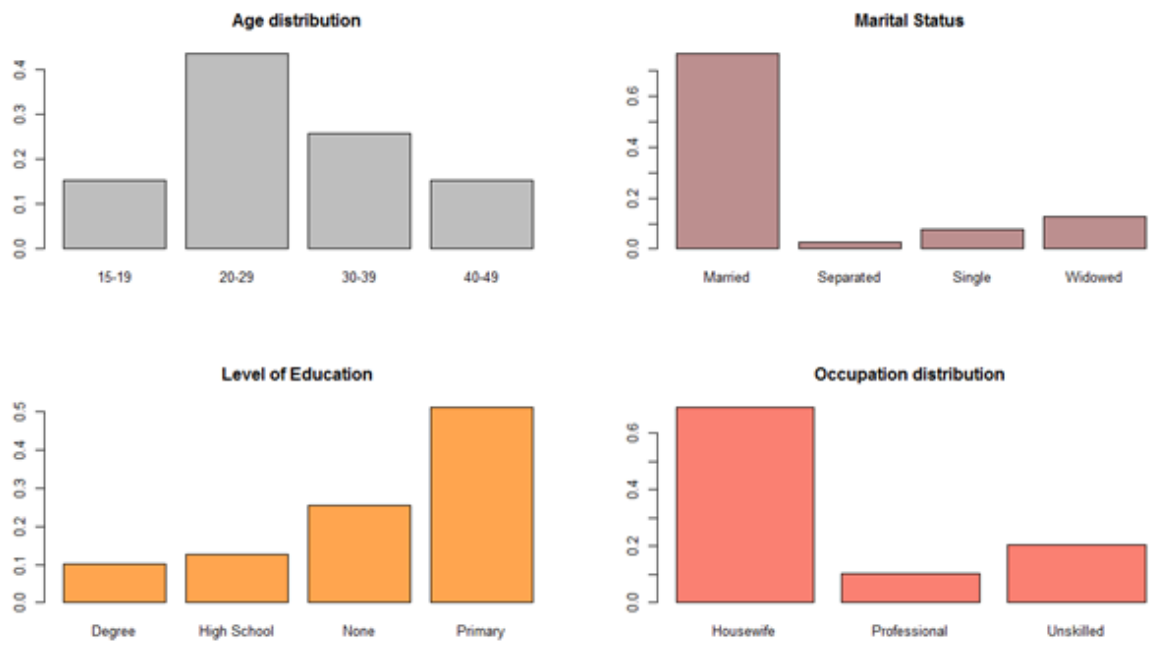

Figure 2: Respondents distribution by age, marital status, level of education and occupation

The researcher wished to understand the respondent's perceptions about Breast Cancer. The respondents were asked to rate the items on a scale of 1 to 5 where 1 represents Strongly Disagree to 5 represents strongly agree. Respondents were asked to tick the number that best described their opinion about breast cancer and screening.

\section{The perception that breast cancer is a curse or caused by witchcraft}

The respondent were asked to rate their perception on whether breast cancer was a curse $46.2 \%$ of the respondents agree that breast cancer is a curse while $41.0 \%$ disagree. Figure 3 shows the distribution of the responses by age, Education levels and by marital status.

A comparison was made across marital status, Education levels and Age. Only 2.5\% Women who are degree holders agreed to this. $7.7 \%$ of the mothers, whose highest education level is upto High School, agree to this, compared to $35.5 \%$ women who never went to school or whose highest level of education is upto primary school seem to believe that Breast Cancer was a curse. Across the different age groups, 5\% of those between $15-19$ years, $12.8 \%$ of those between $20-29$ years, $17.9 \%$ of those between $30-39$ and $7.8 \%$ of those between $40-49$ years agreed 


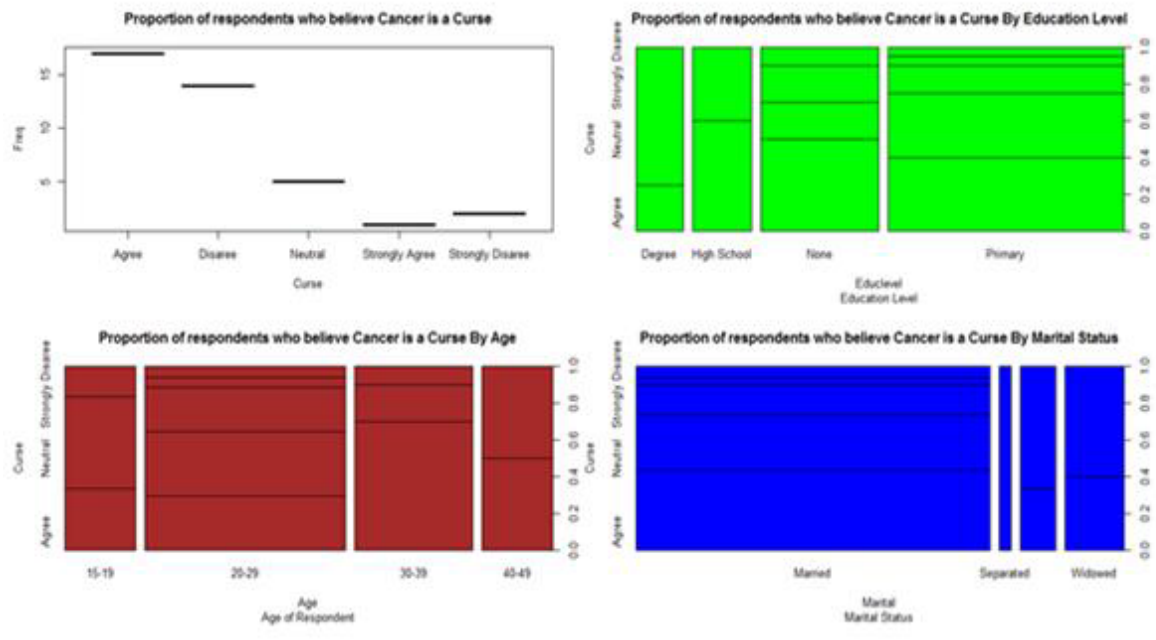

Figure 3: Breast cancer a curse.

that breast cancer is a curse. The study reveals that whereas younger mothers, less than 29 years disagree that breast cancer is a curse, a higher percentage of those who believe that Cancer is a curse are above 49 years. The Spearman's rank correlation coefficient between Curse and Witchcraft was calculated and found to be 0.5182 . The correlation was statistically significant $(\mathrm{S}=4462.4, \mathrm{p}=0.0003016)$ at $5 \%$ level of significance. A Pearson's chi-square test showed the belief on witchcraft is closely associated with the belief that cancer is a curse $\left(\chi^{2}=47.407\right.$, $\mathrm{P}$-value $=0.000)$. This shows that there is a significant association between witchcraft belief and belief that breast cancer is a curse. The mothers in the Child bearing age who believe that Breast cancer is curse also tend to believe that breast cancer is caused by witchcraft. On witchcraft, $56.4 \%$ of the respondents agree that breast cancer is caused by witchcraft, while only $33.3 \%$ disagree Across marital status, education levels and age $2.6 \%$ women who are degree holders agree to this item $7.7 \%$ of the mothers whose highest education level is up to High School, agree to this, compared to $46.2 \%$ women who never went to school or whose highest level of education is up to primary school seem to believe that breast cancer is caused by witchcraft [4]. There was a negative correlation between education and belief that cancer is caused by witchcraft. This correlation is not statistically significant $(\mathrm{R}=-0.1333, \mathrm{~S}=11197$, $\mathrm{p}$-value $=0.4184) .7 .7 \%$ of those between $15-19$ years old, $17.9 \%$ of those between $20-29,17.9 \%$ of those aged $30-39$ and $7.7 \%$ of those aged $40-49$ agree that witchcraft causes breast cancer The was a positive correlation between Age and belief that cancer is caused by witchcraft. This correlation is however not statistically significant $(\mathrm{R}=0.2127, \mathrm{~S}=7778.3$, $\mathrm{p}$-value $=0.1935) .48 .7 \%$ of the married mothers believed that breast cancer is caused by witchcraft. There was a negative correlation between marital status and belief that cancer is caused by witchcraft. This correlation was statistically significant $(\mathrm{R}=-0.3549$, $\mathrm{S}=13386$, $\mathrm{p}$-value $=0.02662$ ).

\section{The perception that breast feeding causes breast cancer}

Does breast feeding cause breast cancer? One of the aims of this research was to establish whether the respondents believed that breast cancer is caused by breast feeding. 33.3\% of the respondents disagree that breast cancer is caused by breastfeeding, while only $2.0 \%$ disagree, $64 \%$ of the respondents were neutral. This seemed to agree with most studies done on the relationships between breast feeding and breast Cancer. According to Rachel King, a health education specialist in MD Anderson's Lyda Hill Cancer Prevention Center research shows mothers who breastfeed lower their risk of pre- and post-menopausal breast cancer. And, breastfeeding longer than the recommended six months can provide additional protection. In a study by the Collaborative Group on Hormonal Factors in Breast Cancer, researchers found that for every 12 months a woman breastfed, her risk of breast cancer decreased by $4.3 \%$. The study compared mothers who breastfed to those who didn't. It also found the 12-month time period could be with either one child or as the total for several children. Furthermore, Australian researchers found that women who breastfed for more than 13 months were $63 \%$ less likely to develop ovarian cancer than women who breastfed for less than seven months. And, women who breastfed multiple children for over 31 months could reduce their ovarian cancer risk by up to $91 \%$ compared to women who breastfed for under 10 months.

Across marital status, education levels and age, $7.69 \%$ of women who were degree holders agreed to this item $2.5 \%$ of the mothers whose highest education level was High School, agreed to this, compared to $17.9 \%$ women who never went to school or whose highest level of education was primary school seem to believe that breast cancer is caused by breastfeeding. $5.1 \%$ of those between $15-19$ years old, $12.8 \%$ of those between $20-29,7.7 \%$ of those aged $30-39$ and $7.7 \%$ of those aged 40-49 dis-agreed that breastfeeding cause's breast cancer. Majority of the respondents $51.3 \%$ were neutral as to whether breast feeding causes cancer or not. There was a positive correlation between education and belief that cancer is caused by breastfeeding. This correlation was not statistically significant $(\mathrm{R}=0.1250, \mathrm{~S}=8645.2$, $\mathrm{p}$-value $=0.4484)$. Across the different age groups mothers $5.1 \%$ of those between $15-19$ years, $12.8 \%$ of those between $20-29$ years, $7.7 \%$ of those between $30-39$ and $7.7 \%$ of those between $40-49$ years disagreed that breast cancer is caused by breastfeeding. $64.1 \%$ of the respondents were neutral on this item. There was a negative correlation between Age and belief that cancer is caused by breastfeeding. This correlation is however not statistically significant $(R=-0.1392, S=11256$, $p$-value $=0.3979)$

\section{The perception that smoking increases the risk for breast} cancer

According to the Collaborative Group on Hormonal Factors in Breast Cancer (2002), Alcohol and tobacco consumption are closely 
correlated and published results on their association with breast cancer have not always allowed adequately for confounding between these exposures. In this item, the research wished to establish whether the respondent believes that smoking increases the risk for breast cancer or not. $66.7 \%$ of the respondents agreed that smoking increases the risk for breast cancer $12.8 \%$ disagreed while only $20.5 \%$ were neutral. Across marital status, education levels and age, $7.7 \%$ of women who were degree holders agreed to this item, $12.8 \%$ of the mothers whose highest education level was high School, agreed to this, compared to $43.5 \%$ women who never went to school or whose highest level of education was primary school believed that smoking was a risk factor to breast cancer. There was a positive correlation between education and belief that cancer is caused by smoking. This correlation was not statistically significant $(R=0.2258, S=7649.2$, $p$-value $=0.1669) .7 .7 \%$ of those between $15-19$ years old, $33.3 \%$ of those between $20-29,17.9 \%$ of those aged 30-39 and 7.7\% of those aged 40-49 agreed that smoking causes breast cancer. There was a positive correlation between Age and belief that cancer causes breast injury. This correlation was statistically significant $(\mathrm{R}=0.3234, \mathrm{~S}=6684.9$, $\mathrm{p}$-value $=0.04463) .53 .8 \%$ of the married mothers believed that breast cancer was caused by smoking. There was a positive correlation between marital status and belief that cancer causes breast injury. This correlation was statistically significant $(\mathrm{R}=0.4389, \mathrm{~S}=5543.6, \mathrm{p}$-value $=0.005187)$.

\section{The perception that breast cancer is an inherited disease}

Could Breast cancer be an inherited disease? The research wished to establish whether the respondents believed that breast cancer was an inherited disease. $69.2 \%$ of the respondents agreed that breast cancer could be an inherited disease, $10.3 \%$ were neutral while only $20.5 \%$ disagreed. Across marital status, education levels and age $10.3 \%$ women who are degree holders agreed to this item $12.8 \%$ of the mothers whose highest education level was upto High School, agreed to this, compared to $46.2 \%$ women who never went to school or whose highest level of education is upto primary school seem to believe that breast cancer was an inherited disease. There was a negative correlation but not statistically significant $(\mathrm{R}=-0.0578, \mathrm{~S}=10451$, $\mathrm{p}$-value $=0.7269)$ between education and belief that cancer is inherited. $7.7 \%$ of those between $15-19$ years old, $33.3 \%$ of those between $20-29,17.9 \%$ of those aged $30-39$ and $10.3 \%$ of those aged $40-49$ agreed that breast cancer was an inherited disease. There was a positive correlation between Age and belief that cancer was inherited. This correlation was insignificant $(\mathrm{R}=0.0553, \mathrm{~S}=9334$, $\mathrm{p}$-value $=0.7383) .56 .4 \%$ of the married mothers believed that breast cancer is inherited, $5.1 \%$ of the single mothers believe that breast cancer was an inherited disease. $7.9 \%$ of the widowed believe that breast cancer was an inherited disease. There was a negative correlation between marital status and belief that cancer was inherited. This correlation was not statistically significant $(R=-0.1655, S=11516$, $\mathrm{p}$-value $=0.3138$ ).

\section{The perception that breast cancer causes breast injury and loss of breasts}

In this item, the researcher wished to establish whether the respondent believes that breast cancer causes breast injury. $5.1 \%$ of the respondents agreed that breast cancer could cause breast injury $30.8 \%$ disagree majority of the respondents were neutral at $64.1 \%$. Across marital status, education levels and age $2.6 \%$ women who are degree holders agreed to this item $7.7 \%$ of the mothers whose highest education level was high school, disagreed to this, compared to $20.5 \%$ women who never went to school or those whose highest level of education was upto primary school seem to believe that breast cancer caused breast injury. $64.1 \%$ of the respondents within different education levels were neutral on this item. There was a positive correlation between education and belief that cancer is causes breast injury. This correlation is not statistically significant $(\mathrm{R}=0.2259, \mathrm{~S}=7649.2$, $\mathrm{p}$-value $=0.1669) .2 .5 \%$ of those between $15-19$ years old, $20.5 \%$ of those between $20-29,5.1 \%$ of those aged 30-39 disagreed that breast cancer caused breast injury. There was a positive correlation between Age and belief that cancer caused Breast injury. This correlation is statistically significant at $5 \%$ level of significance $(\mathrm{R}=0.3239, \mathrm{~S}=6684.9$, $\mathrm{p}$-value $=0.0446) .56 .4 \%$ of the respondents believed that breast cancer causes breast injury. The was a positive correlation between marital status and belief that cancer caused breast injury. This correlation was statistically significant at $5 \%$ level of significance $(\mathrm{R}=0.4389, \mathrm{~S}=5543.6, \mathrm{p}$-value $=0.005187)$. On whether the respondent believes that breast cancer causes loss of breasts $10.2 \%$ of the respondents agreed that breast cancer could lead to loss of breasts while $87.2 \%$ of the respondents disagreed and only 2.6\%were neutral. Across marital status, education levels and age $10.3 \%$ women who were degree holders agreed to this item $5.1 \%$ of the mothers whose highest education level is upto high school, agreed to this, compared to $7.6 \%$ women who never went to school or whose highest level of education is upto primary school disagree that breast cancer is cause loss of breast. There was a weak positive insignificant correlation between education and belief that cancer leads to breast loss, $(\mathrm{R}=0.0556, \mathrm{~S}=9330.9$, $\mathrm{p}$-value $=0.7368) .15 .4 \%$ of those between $15-19$ years old, $38.4 \%$ of those between $20-29,20.5 \%$ of those aged $30-39$ and $12.8 \%$ of those aged $40-49$ agreed that breast cancer causes breast loss. There was a positive correlation between Age and belief that cancer leads to breast loss. This correlation is however not statistically significant $(\mathrm{R}=0.1907, \mathrm{~S}=7995.6$, $\mathrm{p}$-value $=0.2448) .66 .7 \%$ of the married mothers disagreed that breast cancer caused breast injury. $7.7 \%$ of the single mothers and $12.8 \%$ disagreed that breast cancer caused breast loss. There was a weak positive correlation between marital status and belief that cancer causes loss of breasts. This correlation was however not statistically significant $(R=0.0519, S=9367.1, p$-value $=0.7536)$. The Figure 4 shows the correlation matrix for the different perceptions.

\section{Conclusion}

Uptake of cancer screening has been minimal compared to the efforts of the government in encouraging the public to participate

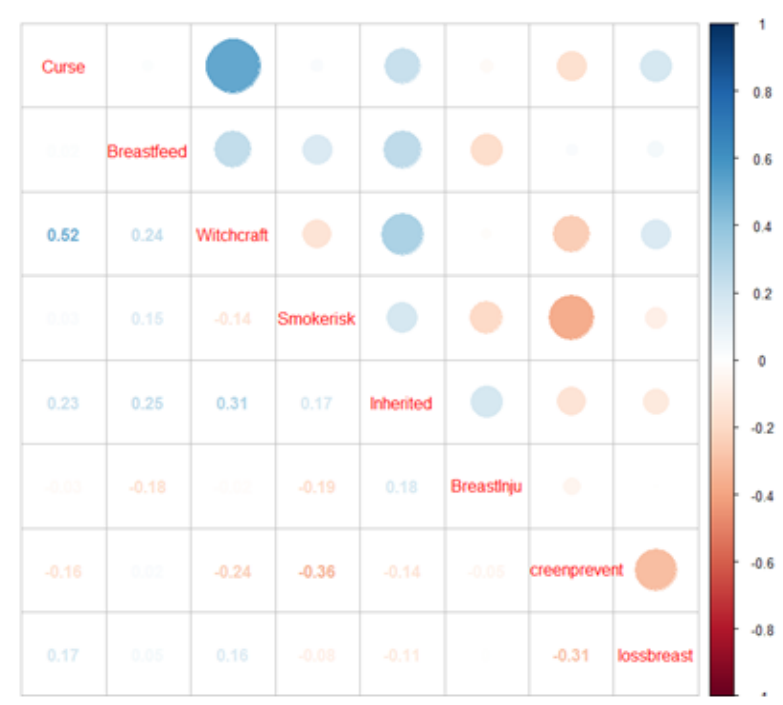

Figure 4: Perceptions correlation matrix. 
Citation: Alii LK (2017) Misconceptions and Perceptions on Breast Cancer Risk in Kilifi South Subcounty. J Biom Biostat 8: 336. doi:10.4172/21556180.1000336

Page 5 of 5

in this cause. The study was aimed at finding whether these efforts have been hampered by the perceptions on breast cancer. The study shows that many of the respondents may not have undergone cancer screening due to the belief and perceptions in the society. The study revealed that whereas younger mothers, less than 29 years disagreed that breast cancer was a curse, a higher percentage of those who believed that Cancer was a curse were above 49 years. The mothers in the Child bearing age who believe that Breast cancer is curse also tend to believe that breast cancer is caused by witchcraft. This probably explains why the uptake of screening services provided by the government in the health centers across the counties has not been effective. There is need for the government to create awareness on breast cancer and to put in place strategies that would mitigate around these perceptions for increase in the uptake screening services by the nearby health centers.

\section{References}

1. Parkin DM, Bray F, Ferlay J, Pisani P (2005) Global cancer statistics. Cancer Journal for Clinicians 55: 74.

2. Farley J, Bray F, Pisan P, Parkin DM (2008) Cancer incidence, Mortality and Prevalence worldwide. Globocan IRAC, Lyon.

3. Kenya Ministry of Health (2011) National Cancer Control Strategy 2011-2016.

4. World Health Organization (2013) Global Health Estimates Summary Tables Projection of Deaths by Cause, Age and Sex. World Bank Income Group and WHO Region, Geneva, Switzerland. 